\title{
Voluntarismo heurístico e historicidad en los estudios de género: un debate epistémico Heuristic Voluntarism and Historicity in
Gender Studies: An Epistemic Debate
}

\author{
Julio Francisco Villarreal \\ Universidad de Buenos Aires \\ j.f.villarrealg@gmail.com
}

Recibido / received: 17/01/2019

Aceptado / accepted: 09/03/2019

DOI: https://doi.org/10.20318/eunomia.2019.4695

\begin{abstract}
Resumen
El presente trabajo provee a indagar respecto a las condiciones metodológicas y epistémicas que limitan la praxis heurística de todo aquel que se vea llamado a indagar sobre los estudios de género. Se sugiere aquí que en tanto el investigador social pretenda cuestionar los límites valorativos, axiológicos y gnoseológicos sobre los cuales se instituye la tradición de los estudios de género, tal investigador deberá poder renunciar, al menos iniciáticamente, a toda pretensión de cientificismo para su obra (a tal fin se apelará, cual ejemplo paradigmático, a la noción de la "performatividad de los cuerpos" de Butler). En tal sentido, se sugerirá que, a fin de cuentas, el costo de oportunidad teórico relativo a tal cuestionamiento puede ser exorbitantemente alto en tanto el mismo suponga coartar la libertad heurística del investigador de referencia. A lo largo de este ensayo, el autor no apelará a bibliografía filiada en el corpus teórico de los estudios de género, sino a contribuciones de la epistemología y la sociología del conocimiento. Por otro lado, tampoco se proveerá aquí a debatir sobre los derechos de aquellos grupos a cuyo análisis se abocan los estudios de género sino, por el contrario, a consideraciones epistemológicas relativas en tal disciplina.
\end{abstract}

\section{Palabras clave}

Epistemología de los estudios de género, sociología del conocimiento, performatividad de los cuerpos, voluntarismo de los estudios de género, historicidad de los estudios de género.

\begin{abstract}
The present work is intended to investigate the methodological and epistemic conditions that may constrain the heuristic realms of anyone who is devoted to the gender studies. It is suggested here that as long as the social researcher intends to question the values, mindset and gnoseological constructs on which the tradition of gender studies is instituted, such a researcher should be able to renounce, at least initially, to any claim of scientism to his work (to such an end, the author will appeal, as a paradigmatic example, to the notion of the "performativity of the bodies" of Butler). In such a sense, it will be suggested that, in the end, the theoretical cost of opportunity related to the abovementioned inquiry can be exorbitantly considerable as long as it supposes restricting the heuristic freedom of the researcher.
\end{abstract}


Throughout this essay, the author will not appeal to bibliography related to the theoretical corpus of gender studies, but to contributions from epistemology and sociology of knowledge. On the other hand, the current essay is not grounded to discuss the rights of those groups which the gender studies attention is focused on, but, on the contrary, it will provide to exert some relative epistemological considerations within such a discipline.

\title{
Keywords
}

Epistemology of gender studies, sociology of knowledge, performativity of bodies, voluntarism of gender studies, historicity of gender studies.

\begin{abstract}
SUMARIO. 1. Introducción. 2. Objetivo. 3. Hipótesis. 4. Metodología. 5. Sobre los problemas epistémicos para los estudios de género. 5.1. Sobre lo que significa hablar de los estudios de género: sus contribuciones sociales y teóricos. 5.2. Sobre los límites gnoseológicos en la noción en la "plasticidad de los cuerpos" de Butler. 5.3. Limitaciones y evasiones a los marcos simbólico-conceptuales de los estudios de género. Sobre los "costos de oportunidad" epistémicos al desafiarse la tradición de los estudios de género. 5.4. Lecturas posibles sobre los límites de la sexualidad. 5.5. Ideología: ¿Una evasión a la tensión entre la tradición gnoseológica y el voluntarismo heurístico? 6. Conclusión.
\end{abstract}

\section{Introducción}

Desde sus comienzos, los estudios de género han dado relevantes pasos a los efectos de denunciar las imposiciones culturales, ideológicas, políticas o económicas que sobre ciertas minorías y grupos pesan. En este sentido, los aportes de tal disciplina han sido, ciertamente, tributarios a un ideario sensiblemente más equitativo e imparcial para con los grupos (mujeres en general, colectivo LGBT) que aquel al que los mismos han sido, consuetudinariamente, relegados. A lo largo de los últimos años, tal aporte es susceptible de ser explicado en virtud del hecho de que, independientemente de que se adscriba o no a los postulados de los estudios de género, estos últimos han promovido un debate respecto a la condición, tradicionalmente relegada, de los grupos de referencia.

En efecto, no han sido pocos quienes han sostenido que el mero hecho de someter a escrutinio o consideración pública las condiciones culturales, políticas o económicas por las que los grupos desaventajados ya mentados han de discurrir, supone una contribución social tanto o más relevante que el proveer a un cambio puntual sobre cada una de las condiciones de referencia. Es en virtud de tal consideración que la prédica de académicas como Phelan debe de ser interpretada. De conformidad a la misma, es justamente el conjunto de valores y axiomas sociales, eminentemente naturalizados, aquellos sobre los que se instituye la exclusión social, e incluso política, de tales grupos. Sin embargo -sostendrá la mentada desde una posición feminista-, del hecho de que un colectivo históricamente desaventajado sea objeto de atención pública no se sigue, per se, que el mismo haya de ser investido con los necesarios atributos del poder que le permitan, justamente, revertir un tal estado de situación: "Si la visibilidad equivaliese al ejercicio del poder, entonces la cultura occidental debería estar regida por jóvenes semidesnudas de tez blanca" (Phelan, 1993: 10).

Paradójicamente -sugiere Phelan desde una tal posición-, del hecho de que el cuerpo femenino sea tributario de la atención que el interés, disfrute y reificación 
masculina sobre el mismo supone no se sigue que una tal condición le permita a un tal colectivo disponer de los instrumentos necesarios para subvertir un tal estado de situación. Ello se debe, justamente, al hecho de que el grupo que habitualmente se beneficia de tal extremo se encuentra invisibilizado en relación a aquellas prácticas que explican y fundamentan la cosificación del cuerpo de la mujer. Contraintuitivamente, por lo tanto, aquellos grupos que son objeto de una publicidad y exposición generalizada son los que se encuentran más estructuralmente desfavorecidos a la hora de poder exponer, públicamente, las condiciones disvaliosas que subyacen a tal contingencia. Es en la alteridad en la que se reflejan las propias limitaciones simbólicas y de derechos sobre las que se explica, justamente, la hegemonía de tales diferencias. En palabras de Phelan (1993: 13): "La identidad (...) es perceptible únicamente a través de una relación con el otro, es una forma de resistir e interpelar a la otredad (...) El mundo visual supone un proceso de ausencias: aprender a ver requiere entrenar con cuidado la ceguera". Es en virtud de tal orden de ideas que bien podría sostenerse que, por lo general, la tradición del pensamiento de los estudios de género ha estado signada por una particular contradicción: muchas de las limitaciones políticas, culturales e incluso gnoseológicas de tal disciplina provienen del propio marco referencial y axiológico al que se apela para examinar aquello que se cuestiona. En otras palabras, en la medida que los estudios de género provean a explicar y dar cuenta de una serie de restricciones que atentan contra las propias posibilidades de desarrollo de tal disciplina, aquellos que se vean llamados a indagar en el mentado campo de estudio deberán abocarse, primera y principalmente, a una genealogía de las propias restricciones metodológicas que subyacen a la propia materia de análisis. El presente trabajo se abocará a estudiar cuáles son tales condiciones; de qué modo pueden ser cuestionadas y, finalmente, cual es el precio o -en última instancia- sanción que quien se aboque al examen de las mismas -en el marco de los estudios de género- deberá afrontar.

\section{Objetivo}

El objetivo del presente opúsculo será, por lo tanto, indagar respecto al alcance de las condiciones y limitaciones gnoseológicas que impiden que los estudios de género logren escindirse e ideológicamente independizarse de algunos de los escollos teóricos que éstos poseen. Entre estos últimos óbices, debe referirse la praxis metodológica preexistente, la bóveda de significaciones socioculturales en virtud de las cuales el propio investigador se formara, las tradiciones y plasmaciones culturales que incidieran sobre el universo social a ser examinado y las propias normas epistemológicas que investigar en el seno de un paradigma científico supone.

\section{Hipótesis}

La hipótesis principal del presente trabajo se filia en la idea de que las posibilidades heurísticas que el investigador posee a los efectos de escindirse de la tradición tanto de los estudios de género como de las propias prácticas y significaciones sociales, supone un costo de oportunidad particularmente alto. En especial para aquellos trabajos que invoquen, para sí, una pretensión de cientificismo.

De conformidad con tal hipótesis, el teórico que se vea llamado al estudio de la mentada disciplina podrá abjurar del conjunto de limitaciones y condicionamientos gnoseológicos y valorativos sobre los que se instituye la tradición de trabajo merced a la cual se ha formado, pero un tal proceder podría suponer severos cuestionamientos al rigor analítico de su trabajo. Ello desde que subyace a la historicidad de las disciplinas y paradigmas científicos una 
retórica epistémicamente autoritaria en tanto excluyentemente (respecto a terceras) legitimante de sus propias prácticas, axiomas y significaciones.

\title{
4. Metodología
}

La presente monografía no pretende, en modo alguno, indagar respecto a las limitaciones gnoseológicas referidas en el parágrafo precedente a partir de un escrutinio de los postulados, aportes y conclusiones provenientes del seno de los propios estudios de género. En otras palabras, aquí se intentará realizar un examen de las mentadas limitaciones a partir de un acervo bibliográfico ciertamente periférico o adyacente al corpus teórico de tal disciplina.

Ello en virtud de dos consideraciones. En primer lugar, porque sería ciertamente inconducente abocarse a la revisión de tal heurística a partir del reexamen de una disciplina ciertamente explorada y comentada, tal vez, en demasía. Sería pretencioso o, peor aún, irreal sugerir que constituye una materia de análisis yerma aquella que, en nuestra inmediata contemporaneidad, conforma una corriente de trabajo ya abultada. En segundo lugar, debido a que abocarse a la investigación de las fronteras de posibilidades del conocimiento de una ciencia, paradigma o doctrina a partir de sus propios postulados podría suponer, antes que un ejercicio epistémicamente redentor, un acto cognoscitivamente opresivo. Los propios obstáculos y valladares teóricos que los estudios de género podrían importar se explican, en última instancia, a partir de la propia historicidad y legado ideológico y metodológico que el ethos axiológico, valorativo y simbólico de campo de conocimiento. En función de ello, la solución que el proceder referido depararía sería de carácter circular y, por tanto, inexorablemente estéril. En conclusión, apelar a tal fórmula podría perpetuar las dificultades teóricas que el presente opúsculo pretende revelar o exteriorizar. Al decir de Barnes y Edge (1982: 10):

\begin{abstract}
"La cultura es mucho más que el marco para la investigación científica; es la propia investigación. Tal cultura no supone únicamente problemas, técnicas y hallazgos culturalmente ceñidos [al paradigma de tal cultura]; también son [culturales] los modos de percibir y conceptualizar la realidad, las formas de inferencia y analogía, y los estándares y precedentes para el juicio y la evaluación que se emplean realmente en el curso de la investigación".
\end{abstract}

En efecto, tal y como sostiene Kuhn, no existen, para una ciencia o paradigma dado, estándares de legitimación y contrastación ajenos a los que tanto la propia disciplina como, -particularmente, la comunidad epistémica que se forma en torno a la misma determina. En pocas palabras, tales paradigmas "están dirigidos no sólo hacia la naturaleza, sino también hacia la ciencia que los produjo. Son la fuente de los métodos, problemas y normas de resolución aceptados por cualquier comunidad científica madura, en cualquier momento" (Kuhn, 2004: 165).

Dada, por lo tanto, la falta de un canon o esquema de ponderación de los postulados y premisas gnoseológicas dentro de un paradigma que sea aséptico a los propios valores del mismo, devendría en un ejercicio fútil, sino lapidariamente aporístico, apelar a estos últimos a los efectos de dar cuenta de las propias limitaciones del universo de significaciones que lo constituye.

Por último, ha de referirse que el presente trabajo no pretende discutir sobre la operativización, puesta en práctica o desarrollo de los derechos de las comunidades LGBT desde una perspectiva eminentemente jurídica. De conformidad a lo ya suscrito precedentemente, la bibliografía existente para una tal materia es por demás copiosa, y, en tal orden de ideas, nada diría o agregaría este artículo. 
Por el contrario, este opúsculo intentará abocarse al análisis de la primera antesala de la materia, indagando sobre la naturaleza de las restricciones y límites al conocimiento que todo teórico puede hallar al momento de debatir sobre los estudios de género desde una perspectiva eminentemente epistémica y no jurídica. La misma se centrará, por lo tanto, en los costos de oportunidad "gnoseológicos" que el dejar atrás la tradición sobre la cual tales estudios de género -y sus pregoneros- se formaran, supone. A tal fin se apelará a un caso paradigmático: la "plasticidad de los cuerpos" de Judith Butler.

\section{Sobre los problemas epistémicos para los estudios de género}

\subsection{Sobre lo que significa hablar de los estudios de género: sus contribuciones sociales y teóricas}

Bien es sabido que a lo largo de las últimas décadas, los estudios de género han realizado considerables avances gnoseológicos en lo atinente a la denuncia del conjunto de presunciones y presupuestos que se encontraban ínsitos en las prácticas sociales hegemónicas. Entre los mismos pueden referirse:

1.- El cuestionamiento de la clasificación, ciertamente estructuralista, relativa a cómo entender la categoría del "género". Tal atributo de la personalidad se filiaría, de conformidad a tal clasificación, en un conjunto monolíticamente cerrado ("masculino" o "femenino") cual universo totalizante de las posibilidades humanas. De conformidad a tal tesis, y tal y como sostiene Carapia (2004: 85), el género no supondría sino un "producto de la asignación de atributos diferenciados entre hombres y mujeres [...puesto que] construye lo masculino y femenino. Esta construcción va consolidando una situación generalizada de inequidades, discriminación y marginación".

Una adscripción ciertamente radical a tal cuestionamiento podría, incluso, objetar algunas de las manifestaciones más elementales de tal heterosexualidad, cual la relación -amorosa- entre individuos de ambos géneros:

Si el amor heterosexual facilita la producción y la institucionalización de las subjetividades que se encuentran ínsitas en el esquema binario masculino/femenino, entonces el mismo reproduce el género. El proceso funciona a través de una forma de subjetivación mediante la cual los sujetos "trabajan" sobre sus subjetividades de acuerdo con los principios de su propia construcción (tales principios están definidos por la "ley" de la diferencia del sexo que, al sostener la heterosexualidad, es perpetuada por los sujetos en su apropiación de los "roles" masculinos/femeninos). En este sentido, podemos decir que la subjetividad está radicalmente condicionada por los principios fundamentales de la heterosexualidad, los cuales determinan la relación amorosa (Johnson, 2007: 101).

2.-Cual directa implicancia de lo suscrito en el punto precedente, los estudios de género han impugnado la forzosa identificación de la sexualidad humana únicamente a partir del binomio hetero u homosexual. Tal y como sostiene Mérida Jiménez (2002: 18):

"La teoría queer apuesta, así, por un desciframiento posmodernista de la noción de identidad sexual que enlaza históricamente con el camino abierto por el feminismo, los estudios sobre la mujer o sobre el género pero que, al tiempo, alienta nuevos 
impulsos y metodologías. Sus propuestas reinterpretan, de manera más radical, los presupuestos de la crítica homosexual -tanto esencialista como construccionista-, pues aplican el análisis deconstruccionista y posestructuralista francés para difuminar (o dinamitar) el binomio hetero/homo. Las personas queer estabilizan los cánones universalistas, transgreden los patrones y subvierten de forma sistemática sus propios límites y los códigos dualistas que definen los comportamientos heteronormativos. La legitimación de los homosexuales como minoría normalizada no es entendida como una victoria sino como una percepción del régimen social que sustenta dominaciones, jerarquías y exclusiones".

Por tal razón, cierta doctrina entenderá que, en lugar de cuestionarse el sistema referencial que determina la sexualidad en virtud del mentado binomio, el mismo podría ser, simplemente, ignorado:

"Respecto a la diversidad de grupos, sucede que mientas algunos luchan por reconocimiento y legitimación, intentando su inclusión en términos igualitarios, otros se preocupan por eliminar las fronteras tradicionales entre género y sexo (cuestionando la división masculino/femenino; hombre/mujer; heterosexual/homosexual). A otros grupos no les interesa cruzar las divisiones y deciden vivir la ambigüedad de la propia frontera" (Arriagada, 2007: 238).

3.- La arbitraria y por demás ingenuamente simplista identidad entre la elección de género y sexo. Tal y como sostiene García (2006: 115):

A través de esta distinción -entre sexo y género- no se niega la existencia de diferencias sexuales (anatómicas y en el placer erótico), sino que lo que propugna la teoría de los géneros es que esta diferencia no marque de forma definitiva la vida humana. En muy estrecha relación con lo anterior, se rechaza entonces que los comportamientos óptimos sean dos, masculino y femenino, con un modelo único de relación entre ellos: el heterosexual".

En el marco de tal orden de ideas, ha de referirse que:

"Los defensores más radicales de esta ideología -relativa a la forzosa identidad entre sexo y género- llegan a afirmar que no existe ni hombre natural ni mujer natural, sino que es la cultura la que impone o atribuye esa identidad al individuo. En otras palabras, consideran que el ser humano nace sexualmente neutro, siendo socializado más tarde como hombre o como mujer en función de un condicionamiento históricocultural. Esto es lo mismo que decir que no existe una esencia masculina o femenina, ni existe una forma natural de sexualidad humana" (Llanes, 2010: 12).

4.- El cuestionamiento de la regulación ética, política y social excluyente a partir de la "heterosexualidad normativa", extremo ya referido. Tal "heterosexualidad normativa" define las relaciones de los sujetos de modo manifiestamente arbitrario, pues limita la expresión de la sexualidad de los mismos a una relación de masculinidad/feminidad insoslayable, siendo el costo social, político y axiológico de trascender tal categoría ciertamente considerable. Tal y como sostiene Mogrovejo (2000: 234):

"La heterosexualidad obligatoria afecta a los hombres y mujeres mediante su definición y la limitación de sus contenidos sexuales. La heterosexualidad normativa como eje de las relaciones de parentesco expresa la obligatoriedad de la convivencia entre hombres y mujeres en condiciones de tasa de masculinidad/feminidad numéricamente equilibrada. Expresa la imposición sobre las mujeres del modelo de sexualidad reproductiva como único modelo que ellas deben conocer y practicar".

Evidentemente, los estudios de género han realizado, tal y como refiere la enumeración que precede, relevantes contribuciones sociales y teóricas. Asimismo, han ampliado las condiciones de posibilidades de conocimiento en virtud de las cuales 
una tal materia podría ser, eventualmente, examinada. Ciertamente, el hecho de que los estudios de género se hayan munido de los aportes de ciencias como sociología, la antropología e incluso la epistemología, constituye, per se, una conquista frente al sentido acrítico por medio del cual tal disciplina era otrora abordada. La dispersión y secularización de las disciplinas llamadas a tal examen constituye una democratización del conjunto de saberes y prebendas a los que grupos cada vez más heterodoxos y amplios pueden apelar a los efectos de indagar en los estudios de género. Tal y como sostiene Plummer (citado por Alfarache Lorenzo):

"En la historia reciente, la reflexión sobre la diversidad sexual humana ha sido en gran medida competencia de la ciencia médica y psicológica. [En los estudios de la materia] suelen colaborar esencialmente autores interesados en la medicina, la psicología y la zoología, mientras los antropólogos, historiadores y sociólogos y los interesados en las humanidades en general suelen brillar por su ausencia. Parece que no podemos pensar en la sexualidad sin recurrir a las imágenes de los cuerpos naturales, los poderosos impulsos, las disfunciones orgánicas y la terminología clínica. El campo de investigación ha sido exhaustivamente medicalizado e individualizado". (Alfarache Lorenzo, 2003: 82)

Aun así, es razonable sostener que incluso si las propias narrativas hegemónicas (tal y como sostiene Plummer: la ciencia médica y la psicología) hubiesen dejado completamente atrás su antaño indeleble impronta en los estudios de género, subsiste, para los mismos, un relevante problema gnoseológico. En este sentido, es plausible sostener, al menos indiciariamente, que, con prescindencia de los propios desarrollos teóricos de la asignatura sub examine, la pretensión -tal vez idealista- de lograrse, por parte de la misma, un decálogo de la sexualidad radicalmente independiente de todo condicionamiento simbólico y cultural puede ser entendida como irredenta. De este modo, no podría liberarse "de dogmatismos la sexualidad para que [la misma] pueda manifestarse autónoma y libremente, desde las diversas experiencias que ella supone, desde los diversos discursos y saberes" (Bodnar, Tovar \& Arias, 1999: 9).

En pocas palabras, los propios criterios analíticos que deberían dar cuenta de las posibilidades de la emancipación de la sexualidad (cual presupuesto para la libre determinación del género y, en definitiva, la autonomía personal) se ven forzosamente sometidos a las mismas restricciones simbólicas y gnoseológicas que restringen a tal sexualidad como objeto de estudio. Tal es, en definitiva, la problemática que anima al presente trabajo: se intentará sostener que, al contrario de lo que pudiera pensarse, es plausible encontrar las cortapisas gnoseológicas mentadas en muchos de los intentos de conceptualizarse un esquema de estudios del género y sexo en función de presupuestos pretendidamente innovadores y, peor aún, liberadores. Para ello se apelará a un caso paradigmático: la "plasticidad de los cuerpos" de Judith Butler.

\subsection{Sobre los límites gnoseológicos en la noción en la "plasticidad de los cuerpos" de Butler}

Pretender que los estudios de género se constituyan como una materia atemporal o universalmente válida supondría concebir a las ciencias y, en definitiva, a los discursos, como una institucionalización de lo incondicionado. Ignorar radicalmente la regulación de las conductas y las prácticas sociales hegemónicas que existen sobre todo colectivo social supone abrazar un ideal cuasiromántico, de conformidad con el cual el investigador hace de su propio voluntarismo un sentido trascendente a las propias tradiciones que lo formaran. En este sentido, y tal y como Rouse (1987: 119) sostiene: "No se trata de sostener que el conocimiento científico no tenga universalidad, sino de reconocer que tal universalidad es un logro siempre enraizado en el conocimiento local inscripto en un contexto". 
Es por ello que al momento de analizarse la retórica de los estudios de género, no puede renunciarse a las usanzas, ritos y significaciones que subyacen a los mismos; incluso de comulgarse con un sentido de manumisión respecto a aquellas tradiciones que desean rechazarse. En tal inteligencia, y en tanto provean a un estado de situación superador a aquel desde el cual se encuentran al momento de realizar toda pesquisa, los estudios de género deben enfrentar el legado o carga simbólica y gnoseológica de ciertos institutos sociales, pero también teóricos, que, de todos modos, son tributarios a la propia historicidad de los mismos. En este orden de ideas, el instituto más relevante no sería otro que la propia ontología de los usos y costumbres que definen a la sexualidad ortodoxa occidental. Al decir de Foucault (1982: 76), la misma no debe ser entendida

"como una especie dada de naturaleza que el poder intentaría reducir, o como un dominio oscuro que el saber intentaría, poco a poco, descubrir. Es el nombre que se puede dar a un dispositivo histórico: no una realidad por debajo en la que se ejercerían difíciles apresamientos, sino una gran red superficial donde la estimulación de los cuerpos, la intensificación de los placeres, la incitación al discurso, la formación de conocimientos, el refuerzo de los controles y las resistencias se encadenan unos con otros".

Téngase nuevamente presente el hecho de que, tal y como sostiene Foucault en su plena literalidad, la sexualidad no puede ser concebida de modo metafísico ("un dominio oscuro") o abstractamente contrapuesta a los designios de la volición humana ("una especie dada de naturaleza que el poder intentaría reducir"). Por el contrario, la misma debe ser entendida como una serie de relaciones ("gran red superficial"), prácticas ("placeres") y valores ("incitación al discurso") que explican, justamente, su materialidad. Por lo tanto, es en virtud de la imposibilidad de aprehender un sentido abstracto y radicalmente voluntarista para entender la sexualidad que, como bien sostiene Fausto-Sterling (2006: 39), las condiciones de posibilidad de una ciencia abocada al estudio de la misma suponen, primera y preeminentemente, una renuncia a la discrecionalidad del teórico, al universo de lo intelectualmente especulativo: "[h]ablar de sexualidad humana requiere una noción de lo material. Pero la idea de lo material nos llega ya teñida de ideas preexistentes sobre las diferencias sexuales".

Se asiste, de este modo, a una doble singularidad: tal y como se refirió en el parágrafo precedente, los estudios de género podrían ser entendidos como una disciplina que permita cuestionar o redimensionar ciertas prácticas y valores sociales. De este modo, los mismos conformarían, en términos de Bourdieu, una "estructura estructurante". Sin embargo, estos últimos también revestirían la condición de ser una "estructura estructurada" -también en los términos del mentado galo- por el universo de significaciones y sentidos (políticos y apolíticos) al que deben, de suyo, interpretar. Sucede que, tal y como acaece en distintos campos, los estudios de género no podrían escindirse completamente del legado simbólico precedente, a contrario sensu de lo que sostiene una vertiente de la sociología del conocimiento ciertamente cuestionable. Nos referimos, claro está, al ecumenismo metodológico de Merton (1973: 273): "El universalismo debe ser afirmado de manera consistente [siendo] un principio guía dominante".

En tal sentido, el deber comulgar, o al menos considerar, la preexistencia simbólica de binarios estructuralistas como aquel que predica el opuesto masculino/femenino, o la potestad de escapar a un conjunto cerrado de categorías -verbigracia, la mentada asociación entre género y sexo- podría, eventualmente, revelarse como una condición insoslayable, $\mathrm{o}$, en términos anglosajones, inescapable, para los estudios de género. ¿Cuál es, entonces, la condición de posibilidad del deseo emancipador para la bóveda de representaciones referenciales 
a la que puede aspirar el trabajo del investigador de la materia? Un pasaje poco explorado de Butler (2002: 56-57) puede ser clarificador en el punto:

\begin{abstract}
"Problematizar la materia de los cuerpos puede implicar una pérdida inicial de certeza epistemológica, pero una pérdida de certeza no es lo mismo que el nihilismo político. Por el contrario, esa pérdida bien puede indicar un cambio significativo y prometedor en el pensamiento político. Esta deslocalización de la materia puede entenderse como una manera de abrir nuevas posibilidades, de hacer que los cuerpos importen de otro modo".
\end{abstract}

Tal y como puede sospecharse, Butler entiende que, en la generalidad de los supuestos, los estudios de género se han filiado en una presunción esencialista en materia conceptualista, de conformidad a la cual toda tesitura que se distancie de las categorías simbólicas consolidadas o aceptadas a los efectos de dar cuenta de la sexualidad y el género (verbigracia, una filiada en el binarismo masculino-femenino) importa un riesgo epistemológico, en virtud de su eventual indeterminación inherente. En otras palabras, para Butler tal riesgo epistemológico se produce por intentarse una emancipación de aquellas categorías ideales que regulan la distribución y uso de los cuerpos como premisa para la definición de un género o sexualidad determinados.

Subyace, por lo tanto, al reconocimiento del mentado riesgo epistemológico de una epistemología del estudio de los cuerpos, una relativa reafirmación, por parte de Butler, de la validez y vigencia de los términos y categorías propios de los análisis a ser superados. Bien podría sostenerse que en tanto la "plasticidad" objete la reformulación de los cuerpos a partir de una materialidad ya dada, las posibilidades con las que contará quien intente determinar los alcances de tal plasticidad se verán severamente condicionadas por dicha materialidad. Ello al menos para aquellos que sean temporalmente coetáneos a tal proceso performativo: acaece que, en tanto disciplina social, los estudios de género deberán batirse con similares problemas con los que cuenta la historiografía, filiados en "la dificultad que impone esa indeterminación, connatural a la novedad del mundo recién aparecido" (Emilfork, 1982: 22)

En otras palabras, en tanto se utilice una categoría conceptual pretérita o, peor aún, presente a los efectos de dar cuenta de un conjunto de relaciones simbólicas, ideológicas o políticas aparentemente superadoras de las anteriores, deviene en plausible que estas últimas no provean sino a perpetuar las categorías reguladoras de la razón eventualmente denunciadas. Naturalmente que tal óbice a una heurística libre o incondicionada no es una heredad excluyente para las cavilaciones de los detractores de la heterosexualidad normativa. Por el contrario, las resistencias estructurales para tal ejercicio contemplativo de nuevas subjetividades provendría, primera y principalmente, del propio logos androcentrista:

"La mente heterosexual no es capaz de imaginar una cultura, una sociedad en que la heterosexualidad no ordene no sólo todas las relaciones humanas sino también la producción misma de conceptos y todos los procesos que eluden la conciencia. La retórica que los expresa (y cuya seducción no desestimo) se envuelve en mitos, recurre al enigma, procede con la acumulación de metáforas, y su función es poetizar el carácter obligatorio de "serás-heterosexual-o-no-serás" (Wittig, 1992: 28).

He aquí, por tanto, un problema, cuya manifestación se hace patente en tanto se coteje el designio redentor-performativo de categorías inmanentemente innovadoras como la mentada "plasticidad de los cuerpos" con la pervivencia de registros androcéntricos que tales categorías, justamente, deberían de poder dejar atrás. En concreto, el hecho de que Butler sostenga que el cuestionar el binarismo hetero-homosexualidad por medio de la plasticidad o performatividad simbólica de los 
cuerpos suponga la posibilidad de incurrirse en un riesgo epistemológico lleva implícita la presunción de que el esquema binario denunciado es inherentemente estable y seguro a la hora de dar cuenta de las posibilidades de manifestación del género y del sexo. Peor aún: conforme a la tesis de Butler, tal esquema podría, incluso, ser gnoseológicamente preferible (en tanto no sea "epistémicamente riesgoso") a aquellas tipologías que se sugieren como superadoras del mismo. Evidentemente, el modo en el cual se articula conceptualmente una categoría del pasado es indiciaria a los efectos de dar cuenta de la relevancia de la misma: tanto como objeto de estudio como premisa reguladora (incluso) de los esquemas gnoseológicos actuales dirigidos a cuestionar los pretéritos sobre los que tal categoría se asienta.

De este modo, para los estudios de género, ciertas estructuras gnoseológicas sobre las que se formara el universo referencial de aquel llamado, incluso, a cuestionarlas pueden eventualmente continuar manifestándose (ocultas o confesas) cual una condición sempiterna. Profesa o inconscientemente se opera la "manipulación de las estructuras simbólicas relativas a [como se representa] la realidad de modo de hacer a esta última consistente con el orden preestablecido" (Schwartz, 1970: 90) del conjunto de representaciones del habitus del propio investigador. Y, por extensión, de la propia disciplina en la que se formara el mismo. En este sentido, sostiene Geertz (citado por Schwartz: ibídem), por "representaciones del mundo" ha de entenderse "el modo en el cual la observación empírica en verdad es percibida, vale decir el modo en el que lo natural, la propia condición y la sociedad [para un observador dado]" se manifiestan. En pocas palabras, el investigador no podría, eventualmente, evitar apelar a las estructuras ideológicas y conceptuales de la realidad empírica a ser descrita o incluso denunciada.

No se trata, por ende, de reconocer la concurrencia de una volición -expresa o implícita- relativa a intentar conciliar o amalgamar un conjunto de tesis bosquejadas por un investigador social dado con aquel paradigma que precediera sus aportes teóricos, sino, por el contrario, de considerar la prevalencia de un marco conceptual sobre el que se definen y construyen las condiciones de posibilidad de la práctica de todo investigador. Debido a las limitaciones que operan sobre este, el mismo no podrá independizarse íntegramente de aquellos esquemas que estructuraran su experiencia sensible y analítica. El recurso a tal experiencia pasada puede llevar inscrito en su propio sensus una ventaja epistémica respecto al universo conceptual de lo abstracto o ignoto. En efecto, dado que tal experiencia estructurará un conjunto de estímulos en virtud de los cuales tal investigador tendrá una propensión a describir una realidad a la luz de aquellas representaciones que le resulten más familiares, existirían buenas razones para asumir que este apelará a las mismas. Ello puesto que, por fuera de tales representaciones, no hay sino un acervo especulativo que en ningún supuesto podrá regir la dimensión de lo contrastable como puede hacerse a partir de la experiencia y el acervo analítico ya explorado.

\subsection{Limitaciones y evasiones a los marcos simbólico-conceptuales de los estudios de género. Sobre los “costos de oportunidad" epistémicos al desafiarse la tradición de los estudios de género}

Recapitulemos: tal y como sostiene Geertz (ibídem: 90), los esquemas conceptuales no sólo se construyen a partir y en función de una estructura empírica dada, sino que, a su vez, reelaboran la misma a la luz del propio sentido que tales esquemas conceptuales les otorgan. Es por ello que, para el caso de Butler, la construcción de una "epistemología de los cuerpos" sobre una praxis o teoría hasta ese momento ignota o eventualmente poco desarrollada en tal materia se revela como una tarea dificultosa y teleológicamente ardua. Del mismo modo que la heurística halla en la 
experiencia un recurso certero a los efectos de evitar apelar a la indeterminación de lo especulativo, un esquema conceptual determinado no puede emanciparse completamente de aquellos precedentes, trayectorias, tradiciones y premisas gnoseológicas bajo los cuales el mismo se formara. Como se mencionara, la condición de "inescapable" del marco conceptual-referencial precedente no solo se manifiesta en el propio conjunto de presupuestos ideológicos en virtud de los cuales se percibe la realidad, sino, incluso en los fundamentos teóricos en virtud de los cuales puede elaborarse una heurística de la misma. Al decir de Barthes (1981: 39):

"Todo texto es un intertexto, otros textos están presentes en el mismo, en distintos niveles, en formas más o menos reconocibles: [se trata] de los textos de las plasmaciones culturales previas. Todo texto es un tejido de citas previas (...) La intertextualidad, como condición para cualquier texto no puede, naturalmente, ser reducida a un problema de las fuentes o las influencias, el intertexto es un campo general de fórmulas anónimas cuyo origen puede difícilmente ser localizado".

En este sentido, toda tesis relativa a la estipulación de un esquema identitario para los estudios de género habrá de hallar, en las premisas conceptuales sobre las que se define, condicionamientos epistémicos. Por lo tanto, la definición de la sexualidad o incluso del género no pareciera ser un producto discrecional de la volición del teórico. En la historicidad sobre la que tal volición se erige hallará la misma sus propias condiciones de posibilidad, por lo que es metodológicamente relevante hacer, en palabras de Rubin (1989: 133-134), énfasis en el hecho de que tales estudios:

\begin{abstract}
"deben referirse a sus contextos históricos y sociales propios, además de un cauto escepticismo frente a las generalizaciones [Podrá, entonces, pensarse...] en términos de fenómenos, tales como las poblaciones, las barriadas, las pautas de asentamiento territorial, las migraciones, los conflictos urbanos, la epidemiología y la tecnología policial. Son estas categorías de pensamiento más fructíferas que las tradicionales de pecado, enfermedad, neurosis, patología, decadencia, polución o del declive y caída de los imperios".
\end{abstract}

Es verosímil considerar la posibilidad de que tal historicidad pueda no ser radicalmente inasible, a fin de cuentas, a la capacidad creativa y especulativa de aquel llamado a estudiarla. En tal sentido, podría sugerirse que el conjunto de tradiciones, legados y derivaciones gnoseológicas, constituya, en definitiva, un recurso maleable, susceptible de ser aprehendido y luego utilizado por el ascendiente ideológico y voluntarista de todo teórico social. Podría sugerirse, en este sentido, que aquel llamado a dar cuenta de la contingencia política y los estudios de género no habrá de tener, forzosamente, una relación eminentemente determinista con tal historicidad, pudiéndose articular relecturas y cuestionamientos al orden simbólico e ideológico preexistente. Sin embargo, la tensión entre aquellas restricciones y las condiciones de libertad heurística de referencia es ciertamente compleja, puesto que:

"la comprensión de la historia [de la sociología del conocimiento] no conduce inevitablemente al relativismo, sino al relacionismo. El conocimiento (...) no es una experiencia ilusoria, aun cuando el mismo se articule en torno a una ideología. El conocimiento que surge de nuestra experiencia (...) aunque no es absoluto, es conocimiento, no obstante. [T]odas las significaciones, en una situación dada, remiten unas a otras, y derivan su significado de esta interrelación recíproca en un marco de pensamiento dado. Tal sistema de significación es posible y válido únicamente para cada experiencia o período histórico, el cual, durante cierto tiempo, proporciona a tal sistema un universo de sentido adecuado. Cuando la situación social cambia, el sistema de normas al que tal experiencia histórica había dado luz previamente deja de ser verosímil. La misma condición se manifiesta con referencia al conocimiento y a su perspectiva histórica. Todo el conocimiento está orientado hacia algún objeto, 
siendo influenciado por la naturaleza del objeto a cuyo estudio se aboca. Pero el modo de aproximación al objeto a ser conocido depende de la disposición del investigador" (Mannheim, 1954: 76-77).

En este sentido, la feliz expresión del sociólogo Klaus Eder permite plasmar el sincretismo que el influjo de un paradigma político o ideológico y la capacidad heurística de aquel llamado a interpretarlo (de conformidad a su propio ethos intelectual y axiológico) puede implicar. Es, por tanto, la construcción de tal "narrativa" (Eder, 1996: 168) la que hace posible, en el marco de una bóveda de presupuestos simbólicos preexistentes, dar cuenta de un conjunto de representaciones dirigidas a influir sobre los mismos.

En tal sentido, por "narrativas" habrá de entenderse toda hermenéutica de la realidad que permita, en virtud de premisas subjetivamente valorativas, adscribirse a una tradición de pensamiento y representación que permita, a posteriori, incidirse sobre la misma. Paradigmas de tales tradiciones serían, en definitiva, doctrinas políticas tanto clásicas (conservadurismo, republicanismo, etc.) como contemporáneas (conservacionismo, ecologismo, feminismo, etc.). En este sentido, tal "narrativa" supone, per se, una estrategia comunicativa (ibídem: 168), que opera al definirse un público, un mensaje y, por sobre toda otra consideración, un corpus de ideas en virtud del cual transmitírselo. Debe, de todos modos, hacerse una relevante consideración en el punto: tal y como las concibe Eder (ibíd), las mentadas "narrativas" no constituyen una elaboración de un universo excluyentemente teórico, sino, por el contrario, preeminentemente político, y, en todo caso, simbólico. Sin embargo, aquí nos encontramos con un viejo problema: el costo de oportunidad, por lo tanto, de poder accederse a una mayor laxitud o discrecionalidad a la hora de soslayar una tradición de pensamiento para una disciplina dada a partir de tales "narrativas" es, justamente, la renuncia a la pretensión de plena cientificidad.

Es por ello que la prosa de los estudios de género y sexualidad no puede ser abstractamente especulativa en virtud de las propias ideas de valor del teórico llamado a dar cuenta de las mismas sin que ello no suponga costos epistémicos para una teoría históricamente situada. Acaece que al margen de nuestra pasión por lo "incondicionado" - tal y como sugiriera Genaro Carrió-, el grado de historicidad de toda tesis sobre sus métodos, premisas y conceptos habrá, muy probablemente, de limitar la discrecionalidad heurística del investigador. El que Butler le atribuya un costo de oportunidad epistemológico a una desarticulación conceptual de toda teoría con los criterios de regulación de la sexualidad precedentes es una prueba, casi confesional, de ello. En este sentido podría resultar obtuso predicar un carácter absolutamente revolucionario para los estudios de género (incluso aquellos más pretendidamente contestatarios) en tanto los mismos respondan a una bóveda de presupuestos teóricos cuya tradición histórica es aquella que tributa a su condición científica o, en todo caso, cientificista. Se manifestaría, por lo tanto, una estricta relación inversa entre la solidez epistémica de una tesis y sus posibilidades de ser la misma gnoseológicamente superadora a todas las formulaciones teóricas precedentes.

\subsection{Lecturas posibles sobre los límites de la sexualidad}

De todos modos, la mentada no es la única lectura plausible y, en tal sentido, bien vale replantearse diversas hipótesis a los efectos de debatir los límites heurísticos (en tanto pretendidamente científicos) de los estudios sobre la sexualidad. A continuación se enumeran: 
1.- La primera de tales hipótesis sería, ciertamente, aquella sugerida por Judith Butler: la propia tradición gnoseológica histórica limita los alcances, densidad e innovación conceptual. Para el caso de Butler, el mentado "costo de oportunidad" epistemológico sería, justamente, la implausibilidad de poder analizar, sobre presupuestos amplios e irrestrictos, la fenomenología de la performatividad de los cuerpos. Explayarse en el punto (ya comentado precedentemente) sería sobreabundante.

2.- Una segunda lectura predicaría que, en todo caso, no necesariamente existe una tal limitación analítica. En este orden de ideas, la determinación o control de los límites gnoseológicos de una teoría no dependerá -al menos estrictamentedel marco conceptual que pueda eventualmente constituirla. Tal y como sostiene Foucault (1977: 123) en un célebre pasaje:

"Los discursos, al igual que los silencios, no están de una vez por todas sometidos al poder o levantados contra él. Hay que admitir un juego complejo e inestable donde el discurso puede, a la vez, ser instrumento y efecto de poder, pero también obstáculo, tope, punto de resistencia y partida para una estrategia opuesta".

En definitiva, el teórico no debe encontrarse necesariamente inmerso en una red de naturaleza conductista en virtud de la cual deba, forzosamente, replicar ciegamente el legado gnoseológico que lo precede. En este orden de ideas, las líneas de investigación y la tradición de una disciplina no necesariamente habrán de ser susceptibles de determinar, por su propio imperio, las fronteras del conocimiento. Por el contrario, tales líneas de investigación y disciplinas podrían ser entendidas como un objeto de inquisición y especulación en virtud del cual el mentado teórico podría, justamente, expandir los ya aludidos límites gnoseológicos.

\subsection{Ideología: ¿Una evasión a la tensión entre la tradición gnoseológica y el voluntarismo heurístico?}

Sin embargo, a la hipótesis referida en el parágrafo precedente subyace una problemática susceptible, por sus propios méritos, de dar lugar a una controversia epistémica de consideración. Acaece que, en tanto el investigador se distancie del corpus teórico de su propia disciplina y provea a definir en virtud de apreciaciones ciertamente subjetivas la fenomenología de la misma, podría incurrir en ciertos juicios de valor. Los mismos, a su vez, podrían suponer una pretensión de reemplazo o incluso superación del núcleo teórico del cual se partiera. Tal y como sostiene Schumpeter, es inherente a la psique humana (por lo que un tal investigador no podría evadirse a tal supuesto) la representación o heurística de una realidad de la que se forma parte en términos inmanentemente subjetivos. En este sentido, el dar cuenta:

"de nosotros mismos, de nuestros motivos, de nuestros amigos, de nuestros enemigos, de nuestra vocación, de nuestra iglesia, de nuestro país, puede tener más que ver con lo que nos gustaría que ello represente que como tales entidades realmente son" (Schumpeter, 2006: 34-35).

Tal consideración, especialmente relevante para aquellos estudios sociales (puesto que los mismos se abocan al análisis de las instituciones a las que refiere el mentado epistemólogo) no debería ser, en rigor de verdad, per se objetable. Ello desde que, en la generalidad de los supuestos, los cambios, crisis e incluso, eventualmente, revoluciones científicas obedecen, en definitiva, al influjo de dicho particularismo o autonomía intelectual. Tal y como sostiene Kuhn (2004: 146-147):

"el nuevo paradigma o un indicio suficiente para permitir una articulación posterior, surge repentinamente, a veces en medio de la noche, en la mente de un hombre 
sumergido profundamente en la crisis (...). Casi siempre, los hombres que realizan esos inventos fundamentales de un nuevo paradigma han sido muy jóvenes o muy nóveles en el campo cuyo paradigma cambian. Y quizá no fuera necesario expresar explícitamente este punto, ya que, evidentemente, se trata de hombres que, al no estar comprometidos con las reglas tradicionales de la ciencia normal debido a que tienen poca práctica anterior, tienen muchas probabilidades de ver que esas reglas no definen ya un juego que pueda continuar adelante y de concebir otro conjunto que pueda reemplazarlas".

Sin embargo, una manifestación tan -al menos en un principio- inocente para la epistemología de los estudios de género como la incidencia de subjetivismo del teórico en el proceso de producción del conocimiento podría suponer deletéreas consecuencias. Ello en la medida de que las mentadas apreciaciones vayan dando lugar, gradualmente, a la emergencia de postulados de carácter eminentemente ideológicos. En este sentido, el decurso de uno a otro supuesto se manifestaría en función de la iniciática aserción, por parte de un teórico, de:

"una coherente serie de supuestos, creencias y valores relativos a un componente de la realidad social [lo cual podría dar lugar...] a que ciertos elementos de una tal realidad social estudiados de un modo selectivo y legitimante [...a los efectos de] restringir la reflexión autónoma y crítica, favoreciendo determinados intereses" (Alvesson, 1991: 209).

En este sentido, no necesariamente debe concebirse a los "intereses" a los que alude Alvesson en función de una perspectiva de carácter marxista (vale decir, referida la misma a una ideología cual imposición de una determinada lectura de las relaciones sociales de producción en virtud de ciertas preferencias de clase). Por el contrario, el propio teórico social puede proveer a la consolidación de una "ideología" en la medida de que haga, estrictamente, ciencia. En efecto, y retornando a Schumpeter (1954: 42):

\begin{abstract}
"las ideas científicas suponen una refracción de las circunstancias sociales dadas a los científicos: el trabajo analítico comienza con el material proporcionado por nuestra visión de las cosas, y es ideológico casi por definición (...) La forma en que vemos las cosas difícilmente puede distinguirse del modo en el que deseamos verlas (...) La inferencia para las ciencias sociales es obvia".
\end{abstract}

Por ende, sería ciertamente equívoco comulgar con un voluntarismo gnoseológico radical. Por el contrario, existen ciertas condiciones que nos conminan a considerar la posibilidad de moderar tal tesitura: "comenzamos a partir del trabajo de nuestros predecesores o contemporáneos, o de las ideas que flotan a nuestro alrededor" (Schumpeter, 1949: 350).

De este modo, incluso si se intentara soslayar o incluso prescindirse de una noción o bien determinista o bien condicionada entre el conjunto de postulados a ser instituidos en una tesis o teoría dada y la tradición que informara eventualmente a la misma, una tal tradición devendría en un severo condicionamiento material para el voluntarismo del investigador. En el mejor de los supuestos, e inclusive si se aceptase la tesis relativa a que la historicidad de un conjunto de sucesos o representaciones sociales es inmanentemente dúctil o maleable a los designios de aquel llamado a explicar el corpus de una disciplina dada, deberían hacerse severas concesiones metodológicas.

De este modo, toda novedosa teoría o conjunto de postulados de una disciplina dada debe sortear, inicialmente, el desafío o cuestionamiento inmanente a los mandatos o presupuestos teóricos dominantes. De este modo, ya sea el caso de las ciencias exactas (por caso, la física atómica o el clásico ejemplo de Kuhn relativo 
a la teoría copernicana) o sociales (verbigracia, la filosofía mecanicista) los pregoneros de nuevas áreas o disciplinas del conocimiento deberían afrontar relevantes costos de oportunidad. Por un lado, debieron y deberían de enfrentarse a la falta de aprobación o siquiera validez gnoseológica primigenia de sus postulados de conformidad a las tesis mayoritariamente aceptadas. Por el otro, hubieron de aceptar, en un principio, que sus aportes teóricos no supusieran, de conformidad a los postulados de los paradigmas hegemónicos, ser conducentes o siquiera útiles a los efectos de la resolución de los problemas teóricos que se discutían en el seno de las disciplinas estudiadas. Tal extremo, sumado al hecho de que, sostiene Kuhn, en la generalidad de los supuestos la validez de una tesis determinada no dependa de criterios de evaluación sino inmanentes a un tal paradigma hegemónico importará que, en definitiva, "la competencia entre paradigmas no es el tipo de batalla que puede ser resuelto por pruebas [puesto que...] Ninguna de las partes dará por sentadas todas las suposiciones no empíricas que necesita la otra para poder desarrollar su argumento" (Kuhn, 2004: 230).

\section{Conclusión}

Independientemente del hecho de que el teórico quede sometido en mayor o menor medida a los mandatos epistémicos de su disciplina, el estudio del modo en el que las estructuras de conocimiento limitan nuestro conocimiento excede, ciertamente, la producción intelectual propia de los estudios de género.

A lo largo de la historia de las ciencias, las distintas comunidades epistémicas han establecido códigos, límites y sistemas de premios y castigos de variada índole para aquellos que comulgaran o, por el contrario, se distanciaran de las prescripciones que dictaran tales comunidades. Sin embargo, también es cierto que, para las propias disciplinas en las que operaban tales camarillas, muchos investigadores y teóricos lograron sustraerse de la red de reglas y preceptos que tales grupos buscaron, desde antaño, imponer. Pioneros de la computación como Alan Turing, biólogos como Francis Crick o genetistas como McClintock lograron realizar aportes cuyas credenciales fueron nominalmente suficientes como para cuestionar las estructuras de conocimiento hegemónicas de las distintas disciplinas que, hasta entonces, definían una tradición de investigación y praxis científica monolítica.

En este sentido, el propio cuestionamiento de las estructuras disciplinarias que rigen la absoluta pluralidad de la vida social constituye, sin duda, un necesario primer paso a los efectos de contribuir a tal empresa. Parafraseando a Foucault, la cárcel, el hospital, las fuerzas armadas o las órdenes religiosas son ciertamente instituciones que proveen al desarrollo de corporaciones disciplinarias que pueden limitar la autonomía de aquel llamado a investigar o cuestionar un paradigma dominante. Sin embargo, también conforman tales corporaciones las mentadas comunidades epistémicas que suscriben a $-y$ en virtud de ello, proveen a imponer- una determinada hermenéutica del género y de la sexualidad, y, por extensión, de institutos como la familia, la adopción y el matrimonio.

En la medida de que tales comunidades epistémicas supongan ser una refracción de una corporación disciplinaria mayor (la propia institucionalidad científica) deberá considerarse, en última instancia, cuáles son los costos de oportunidad de cuestionar barreras culturales como la mentada heterosexualidad normativa, la posibilidad del matrimonio igualitario o la identidad de género, entre muchas otras. En este sentido, deberá ponderarse cuánto se está dispuesto a pagar por la adscripción a un ethos científico de un conjunto de valores (los cuales, naturalmente, son histórica y culturalmente situados) en pos de renunciar a las condiciones de posibilidad de una disputa dialéctica, política pero también teórica en torno a la consecución, legitimidad 
y positivización jurídica de ideas que pueden entenderse (o no) como intrínsecamente valiosas o meritorias. A indagar sobre tales costos de oportunidad, desde una perspectiva eminentemente epistémica (puesto que las restantes, como se explicara, han sido por demás frecuentadas), ha intentado contribuir este trabajo.

\section{Bibliografía}

ALFARACHE LORENZO, A. G. A. (2003), Identidades lésbicas y cultura feminista: una investigación antropológica, Plaza y Valdes, México.

ALVESSON, M. (1991), "Organizational symbolism and ideology", Journal of Management Studies, núm. 28 (3), pp. 207-226.

ARRIAGADA, I. (2007), Familias y políticas públicas en América Latina: una historia de desencuentros, United Nations Publications, Nueva York.

BARNES, B. \& EDGE, D. (1982), Science in Context: Readings in the Sociology of Science, Open University Press, Buckinghamshire.

BARTHES, R. (1981), "Theory of the Text". En: YOUNG, R., Untying the Text, Londres, Routledge, pp. 31-47

BODNAR, Y., TOVAR, E., y ARIAS, R. L. (1999), Cultura y Sexualidad en Colombia: un espacio para leer relaciones de poder, formación de actitudes y valores humanos, Universidad Distrital Fr. J. de Caldas, Bogotá.

BUTLER, J. (2002), Cuerpos que importan. Sobre los límites materiales y discursivos del sexo, Paidós, Buenos Aires.

CARAPIA, J. D. (2004), Perspectiva de género, Plaza y Valdés, Madrid.

CARRIÓ, G. R. (2001), Sobre los límites del lenguaje normativo, Astrea, Buenos Aires.

EDER, K. (1996), The Social Construction of Nature: A Sociology of EcologicalEnlightenment, Sage, Londres.

EMILFORK, L. (1982), "La doble escritura americana de Oviedo", Revista Chilena de Literatura, núm. 19, pp. 21-38.

FOUCAULT, M. (1977), Historia de la sexualidad 1: la voluntad de saber, Siglo XXI, México.

FUSS, D. (1991), Inside/out. Inside/out: Lesbian theories, gay theories, Routledge, Nueva York.

GARCÍA, Y. H. (2006), "Acerca del género como categoría analítica", Nómadas Revista Crítica de Ciencias Sociales y Jurídicas, núm. 13 (1), pp. 111-120.

GEERTZ, C. (2012), Life among the Anthros and other Essays, Princeton University Press, New Jersey.

JOHNSON, P. (2007), Love, heterosexuality and society, Routledge, Londres.

KUHN, T. (2004), La estructura de las revoluciones científicas, Fondo de Cultura Económica, Buenos Aires.

LLANES, M. I. (2010), Del sexo al género.La nueva revolución social, EUNSA, Navarra.

MANNHEIM, K. (1954), Ideology and Utopia. An Introduction to the Sociology of Knwledge, Routledge, Londres.

MÉRIDA JIMÉNEZ, R. M. (2002), Sexualidades transgresoras: una antología de estudios queer, Icaria Editorial, Barcelona.

MERTON, R.K. (1973), The normative structure of science, The University of Chicago Press, Chicago.

MOGROVEJO, N. (2000), Un amor que se atrevió a decir su nombre: La lucha de las lesbianas y su relación con los movimientos homosexual y feminista en América Latina, Plaza y Valdés, México.

PHELAN, P. (1993), Unmarked: The politics of performance, Routledge, Londres. 
ROUSE, J. (1987), Knowledge and Power: Toward a Political Philosophy of Science, Cornell University Press, Nueva York.

RUBIN, G. (1989), "Reflexionando sobre el sexo: notas para una teoría radical de la sexualidad”. En: VANCE, C., Placer y peligro. Explorando la sexualidad femenina, Madrid, Talasa, pp. 113-190.

SCHUMPETER, J. A. (1949), "Science and ideology", The American Economic Review, núm. 39 (2), pp. 346-359.

SCHUMPETER, J. A. (1954), History of economic analysis, Routledge, Londres.

SCHUMPETER, J. A. (2006), History of economic analysis, Routledge, Londres.

SCHWARTZ, G. (1970), Sect ideologies and social status, University of Chicago Press, Chicago.

WITTIG, M. (1992), The Straight Mind and Other Essays, Harvester Weatsheaf, Nueva York. 